\title{
E-C Advertisement Translation on Communicative Translation and Semantic Translation Theory
}

\author{
Xuedong Shi \\ Foreign Language Department, Beijing Information Science \& Technology University, Beijing, China
}

\begin{abstract}
Advertisement has been playing a more and more important role in both our life and society because of the world's commercialization and globalization. So there is an urgent need to study on which way is better for advertisement translation. According to Newmark's theory, communicative translation tries to produce the same effect to the readers as the original readers who read the SL. While semantic translation attempts to translate word for word without even changing the sequence or the structure of word and sentence in SL, regardless of the cultural background of readers who read TL. This paper may serve a discussion about the question which way of translation, communicative or semantic translation can be best taken advantage of to translate advertisement.
\end{abstract}

Index Terms — advertisement translation, communicative, semantic

\section{INTRODUCTION}

In the past twenty years, the domestic research of advertisement translation has achieved great success. After a comprehensive study of the articles and works on advertisement translation, the study of advertisement language and advertisement translation in the past twenty years in China can be divided into two stages. Since the research on this respect is a developing course, there is no clear or absolute borderline of such a division. From the middle to the end of the 1990s can be regarded as the first stage. Lots of scholars and translators began to deal with advertisement translation with some certain translation principles or procedures. However, their main concern is whether the advertisement language or translation is beautiful or not. On the other hand, few researches were under the guidance of a definite translation theory; most of them studied with the methods of induction and exemplification. The past ten years sees a deepened research and a fast development of advertisement translation study in China. Some factors like: different kinds of western translation theories introduced in China, more researchers engaged in advertisement translation study with translation theory pushed the further development.

Of course, there were scholars analyzed advertisement translations applying Newmark's theory. Vocative function is one of the text functions that Newmark once put forward and it was used to analyze advertisement translation. That is to say that a translator has the responsibility to revise or recreate the advertisement when there are obscurities in the original advertisements regardless of the personal style or text style of the original. The aim of such "recreation" is to put the readers as the highest priority so that the translation would be in line with the cultural customs and cater to the TL readers.

To draw a conclusion, over the past years, advertisement translation studies in Chins have became more and more mature. Although so many scholars study the procedures of advertisement translation, few of them paid much attention to the applying of Newmark's communicative and semantic translation. This paper would try to explore how these two ways of translation can be applied in advertisement translation. After a general review of the researches of predecessors on advertisement translation, the author realized that the study of advertisements in China needs to be expanded and deepened. However, few has applied semantic and communicative translation to analyze advertisement translation or discussed whether they are proper to be used in advertisement translation.

\section{OBjeCtives AND Methodology}

With the world's commercialization and globalization, advertisements have almost entered every aspects of life. They play an important role in enlarging markets, promoting sales and building a certain group of consumers.

It is not hard to find that there are an increasing number of foreign goods entered our life. Translation needs of those foreign brands or slogans are becoming more and more urgent, and a well-translated advertisement is of great importance to a company. Foreigners will recognize Chinese brands through translations of advertisements. As a consequence, there is now a fierce competition of advertising because advertisements indeed play a more significant role in international market enlargement and attracting foreign consumers. A higher demand for well-translated advertisement is emerging.

Peter Newmark, a prominent figure in the field of translation, made his great contribution because of his putting 
forward of communicative translation and semantic translation theory. Following Cicero, St. Jerome, Luther, Dryden, Tytler, Herder, Goethe, Schleriermacher, Buber, Newmark proposed his definition of communicative translation and semantic translation in Approaches to Translation: communicative translation attempts to produce on its readers an effect as close as possible to that obtained on the readers of the original. (Newmark, 2001). Such a theory is appropriate for advertisement translation study. Communicative translation regards the persuasive function of advertisement in the TL as the highest priority in translation. It also takes the foreign elements, norms of TL and messages within SL into consideration so that rhetoric features in SL can be best presented. While semantic translation can help to realize informative function of advertisements. (Newmark, 2001) The author holds that the two ways of translation, communicative and semantic translation, the former one may best serve to translate advertisements as its requirements meets the persuasive function of advertisements and rhetoric features can be better presented. In this paper, some detailed examples will be presented to show the effect of the best way of advertisement translation.

\section{A BRIEF INTRODUCTION TO ADVERTISEMENT}

The origin of the word: advertisement is "advertere" in Latin. Nowadays, there are many doctrines of explanation to this concept, which are literally different but similar in meaning: the advertisement is an activity of spreading information that are often provided by certain investors through media. (Newmark, 2001) We can see that there are some basic components within the definition of advertisements: (1) advertisements are for the mass consumers, (2) advertisements are for spreading information, which can be something about products or service. They can also be used in fields like economical, political, religion or social concepts. (3) They are shown to people through media, such as TV program, newspapers, magazines and so on. (4) They are sponsored by a certain people or a group for some purposes, which mainly are promoting products or gaining profits.

In our modern society advertisements have been imposing a great influence upon economical and life. Advertisements can be found almost everywhere, including television, newspapers, magazines and even wrappings, etc. although the aim of advertisements is to sell products, its functions doesn't stop there. It practice, that is where it starts. Therefore, it is necessary to study the functions of advertisements, which may fall into five categories:

a. The information function

There is no doubt that consumers firstly need to know which products are exact what they want, so the information would be real, detailed and understandable; making the customers know what the products are how is the service. After the consumers get the information about products and service, it needed to arouse their desire to buy and make them curious and then, they feel they need to spend money. The demand creation is such formed.

b. The persuasive function

Once the consumers are willing to have a try but they aren't sure whether the products are as good as the description, they will hesitate. The advertisements help to persuade or courage them to buy. It doesn't mean that they are forced to buy by the producer. Consumers are also persuaded to establish a good corporation identity in their mind by advertisements, which can help to set up their confidence and a belief of high-quality products and services.

c. The economical function

People are invited to try new products so that in long term fewer people buy obsolete ones. In this way, they accelerate the success and failure of products. Providing the information of new products and their prices, buyers are aware of applying new technology and are more willing to buy them, so the competition between firms become fierce. It is possible that products are developed but prices are lower. The rise of a certain brand is also a showcase of its economical function.

d. The social function

Advertisements play a role in society and it is one of the major forces which can help to foster growth and understanding of important social issues. They could open another window for us to learn about the society. They also inform us of new and improved products and teach people how to use these innovations. By advertisements, consumers compare products and decide what to buy. Fashion trend also can be reflected.

e. The educational function

Through advertisements we can know the advancement of our society. The charity advertisements can be taken as an example. There are charity advertisements which remind us of saving water, loving peace, protecting environment around us, caring the disabled and the elder and so on. People are more aware of such social problems so that they will take action.

Now let us study the rhetorical features of advertisement. Metaphor is a common-found rhetoric in advertisements A metaphor compares two things, which may be quite different, because one has a characteristic that is similar to the other. My ocean. What a simple slogan. This is an advertisement of perfume for women. Ocean is metaphor of women or one's girlfriend. The producer encourages men to buy his girl friend such a perfume. According to Newmark's analysis, five possible procedures using communicative or semantic translation in translating standard have been put forward. (Newmark, 2001)What is his opinion of translating metaphor and simile using communicative and semantic translation will be discussed in the next part.

Sometimes we may find it difficult to understand puns in English, because a pun is usually a humorous use of a word in such a way as to suggest two or more of its meanings or the meaning of another word similar in sound. Puns are often 
used in advertisements so that the propaganda of a certain product becomes more implicit and provide a larger space for consumers to imagine. (Nida, 1998) From Sharp minds come Sharp products. One of the original meanings of sharp is wise and acute. Sharp is also a brand of digital products. So here sharp is a pun which means a group of wise and acute people produce products of sharp, so such digital machines are of high quality.

Probably we could find some clues why parallel is among the best choices of propaganda in Chinese. Two or more words, phrases, or clauses that are similar in length and grammatical form appear together, which is the usual structure of parallel. In such a way, advertisements have stronger imposing manner. We could also find the similar effects using parallel in advertisement. Here is an example: more services, more data, more revenue. Less cost, less time, less space, less complex. Lucen can help make your network more profitable. Through parallel, almost all the advantages of Lucen Technologies are shown.

Some advertisement creator may good at applying antithesis to advertisements. "Sweet, Smart\& Sassy" this is a short but excellent advertisement of an orange company in Florida.

In language, alliteration refers to the repetition of a particular sound in the first syllables of a series of words or phrases. Health, Humor \& Happiness... Gifts we'd love to give.

\section{Newmark's Communicative Translation and Semantic Translation}

The main contribution of Peter Newmark is that he analyzed two ways of translation: communicative translation and semantic translation, in a detailed way. Here the definition of these two ways of translation should be mentioned: communicative translation attempts to produce on its readers an effect that obtained on the readers of the original. Semantic translation attempts to render the exact meaning of the original. (Newmark, 2001). Theoretically speaking, they are quite different from each other. Communicative translation focuses on readers, taking explaining the obscurities into consideration and expecting to make the translation smoother, briefer and more understandable. Such translation should respect the culture background of the readers so some foreign element would be transferred where necessary. On the other hand, adopting communicative translation doesn't equal to ignoring the syntactic equivalence. What is more important is that in order to make the translation conform to the form of target language, the translator would be free from the regulations of source language, transferring foreign elements to local expressions while making easier for readers to understand. Here the source language would play a part as material basis that should be respected by the translators. For example, the Chinese translation of "as poor as a church mouse" should be "yi pin ru xi" (as poor as been washed). The figure within this metaphor was replaced so that translation becomes more acceptable to readers.

Semantic translation addresses itself to analyzing the meanings of words and sentences in source language, trying to make the semantic and syntactic structures of translation as close as the source language. It remains within the original culture while not allowing changing any local expressions of the source language. Since semantic translation strives to retain the distinguishing features and special expressions of source language, it shows writer's thought-process in a best way. Thus, semantic translation tends to be more complex, more awkward, more detailed, more concentrated and more specific than the original, to include more meanings in its search for one nuance of meaning. (Newmark, 2001) But what are the other differences between communicative and semantic translation? In communicative translation, the main meanings of the message should be transferred and the main goal of communicative translation is the translation of meanings. Here which way is better is not what we discuss, what we know is that although meanings within these expressions could both be transferred, it is more understandable whether on the respect of cultural background and syntactic structures. We can also draw a conclusion that in communicative translation, translators are loyal to target language norms while in semantic translation, translators are loyal to the author of source texts. On the other hand, the semantic translation has its own character that it attempts to recreate the exact flavor and tone of the original, one of the reasons is that the form and content are more important. Although the translators try to do almost word-for-word translation in semantic translation, a loss of meaning may be inevitable. (Hatim, 2001)

Newmark also stated that different styles of writing are suitable for different kinds of ways of translation. Most non-literal writing, journalism, popular fiction are suitable for communicative translation, while writings such as philosophical, religious, political, scientific, technical or literary need to be translated semantically. (Newmark, 2001) Common sense or the information free from cultural restrictions can be either translated by communicative translation or semantic translation. Translators therefore should emphasize both content and form of information in translation. To handle the materials concerning religion, philosophy, art and science, the two translation methods can basically prompt similar effects because the materials are the knowledge quite familiar to SL readers and TL readers as well.

Although there are differences between communicative and semantic translation and they have their own features, we cannot perceive them separately. The precise concepts of semantic and communicative translation may be well-explained in this part, so were the differences between them.

The concepts of semantic and communicative translation are two main contributions to general translation theory. As people have long believed that language is purely a social phenomenon, they ignored that there exists a close relationship between the structures of grammar and semantic structure and the expression of thoughts.

In Newmark's following study of communicative and semantic translation, some main points have been put forward. The deeper understanding of the two ways of translation is definitely further explained.After presenting the definitions of interlinear and literal translation, he figured out: the basic difference between semantic and literal translation is that 
the former respects context, the latter does not. (Newmark, 1981/2001)

\section{Case Study of Communicative Translation and Semantic Translation in Advertisement Translation}

It is believed that rhetoric makes expressions more vivid and impressive, so it is widely used to leave readers deeper impression, make sentences more understandable and persuasive. The functions of rhetoric just meet the requirements of advertisements, so Advertisements have such features. Rhetoric plays a role to bridge the concrete products and the abstract advantages of products. On this respect, a successful advertisements translation of rhetoric is of great importance.

a. Translation of Metaphor Appeared in Advertisements

A metaphor is a literary figure of speech that describes a subject by asserting that it is, on some point of comparison, the same as another otherwise unrelated object, achieving their effects via association, comparison or resemblance. It is more implicit and concise, leaving the reader much space to imagine and think about the real aim of advertisements. The proper translation of it will also add vividness and appeal to the target language. Newmark has put forward five possible procedures or solutions in translating metaphors. With the directions of these five solutions, we need to judge which solution is proper to translate a certain advertisement. (Newmark, 2001)

(1) Sophisticated, sweet-to-drink Pink Lady.

Gaogui jingzhi, ke kou de hong fen jia ren.

This is an advertisement for wine. We know that communicative translation focuses on readers, taking explaining the obscurities into consideration and expecting to make the translation smoother, briefer and more understandable. However, tenor and vehicle within this simile are properly acceptable for target language readers; using the first solution is enough to meet the requirements of producer. It is translated semantically. The translator achieves the equivalence of sentence pattern and respects the author.

(2) EBEL, the architects of time.

Yī bèi ěr shǒu biăo shí jiān de dì zào zhě

Less words are used but high quality and extraordinary features are presented. We can see that the vehicle in the target language is changed. This solution is the second solution that was put forward by Newmark. The second procedure is applied here, which is to translate with a different image that has the same sense. If we translated this as:

Yī bèi ěr shǒu biăo shí jiān de jiàn zhù shī

This is treated semantically; Chinese consumers probably cannot understand the goal of this propaganda. Here I am not praising or degrading neither ways of translation. The goal of such analyze is discussing how to make the advertisement translation better. Communicative translation would be proper when we need to transfer the images.

(3) My ocean. (My ocean Club Med Eau de toilette for her)

Wǒde hăi yáng

The tenor is girls or women, while the vehicle is ocean. This advertisement gives consumers a feeling that if a boy buys his girlfriend this perfume, this girl is quiet valuable for him, but it seems that a simple translation used semantic translation like this cannot totally meet the requirements of this advertisement.

As for the culture background respect, the vehicle, ocean, can be well understood by target language readers. However, for such a metaphor, the sense - one's beloved woman behind the image — ocean should be fully interpreted that the TL readers can understand the real goal of this advertisement. Such a translation meets the fifth procedures in translating standard. If we translate it communicatively used the fifth solution, the translation will be:

zhì wǒ de hăi yáng wǒ shēn ài de tā

b. Translation of Pun Appeared in Advertisements

The definition of pun may be described as: a play on words, either on different senses of the same word or on the similar sense or sound of different words. Sometimes we find it difficult to understand puns in English. On the other hand, the advertisement creator are fond of use it to produce a effect of tricky, interesting and impressive. As a consequence, a good translation of puns in English advertisements is indeed necessary and valuable for both producers and consumers.

You will go nuts for the nuts you get in Nux.

Xiăng yòng páij iān guǒ gāo xìng dé bù dé liăo

Nux is a brand of nuts. This advertisement is easy to read and impressive. The two "nuts" appeared in this advertisement form a pun. "Go nuts" means " go wild". The following "nuts" means nuts of Nux. But it seems that we cannot create the same effects in translation. It is translated semantically and the double meanings are well explained. Since there exist no culture overlap, the translator needn't add any cultural equivalence. Applying semantic translation in advertisement translation to show puns appeared in ads, we may not get an outstanding effect or the full meanings of puns cannot be presented. Only when syntactic structures in SL are also acceptable in TL can we translate puns in advertisements semantically. Otherwise, communicative translation is recommended.

c. Translation of parallel appeared in advertisements

Two or more words, phrases, or clauses that are similar in length and grammatical form appear together, which is the usual structure of parallel. In such a way, advertisements have stronger imposing manner. We could also find the similar effects using parallel in advertisement. a successful translation of parallel in advertisement will create the same 
impressive effects in TL.

\section{CONCLUSION}

There is no doubt that advertisements have become one part of our life. They provide information of various products through different media. Not only that, they explain to consumers the usage of products and how to enjoy a service. Probably, they bring more advantages to entrepreneurs. The most obvious one is that through stimulating consumers' desire to buy, they gain profits. With all these informative, marketing and social functions, advertising is one dispensable part in the modern world. However, different types of advertisements not only give rise to failures or misunderstanding in intercultural communication but also pose headaches to translation theorists and translators. Translators usually feel frustrated when encountering the nonequivalence and untranslatable advertisements. Although the problem of limited equivalence and untranslatability do exist, they are much more relative and in a dynamic process. Such translation difficulties can be eased by proper translation strategies and improvement of social environment.

\section{REFERENCES}

[1] Allgela Goddard. (1998). The Language of Advertising. London \& New York: Routledge.

[2] Brown and Gorge Yule. (2000). Discourse Analysis. Beijing: Foreign Language Teaching and Research Press.

[3] Hatim, Basil. (2001). Communication Across Cultures-Translation Theory and Contrastive Text Linguistics. Shanghai: Shanghai Foreign Language Education Press.

[4] Goddard,Angela. (1998). The Language of Advertising. New York: Routledge.

[5] Leech, GN.(1996) English in Advertising. A Linguistic Study of Advertising in Great Britain. London: Longman.

[6] Mueller,B, International Advertising. (1996). Communicating Across Culture. London: Wadsworth Publishing Company.

[7] Nida,Eugene A. (1964). Towards a Science of Translating. Leiden: E.J.Brill, 1964.

[8] Nida,Eugene A. (1981). Meaning Across Cultures. Maryknoll: Orbis Books.

[9] Nida,Eugene A.(1993). Language, Culture and Translating .Shanghai: Shanghai Foreign Language Education Press.

[10] Nida, Eugene A. (2004). Language and Culture: Contexts in Translating. Shanghai: Shanghai Foreign language Education press.

[11] Nida, Eugene A. (2004). Toward a Science of Translating. Shanghai: Shanghai Foreign Language Education Press.

[12] Nida,Eugene A. (1998). Language Culture and Translating. Huhhot:Inner Mongolia University Press.

[13] PeterNewmark A. (2001). Textbook of Translation,. Shanghai: Shanghai Foreign Language Education Press.

[14] Peter Newmark. (2001). Approaches to Translation. Shanghai: Shanghai Foreign Language Education Press.

[15] Wi1ss, Wolfman. (2001). The Science of Translation-Problems and Methods .Shanghai: Shanghai Foreign Language Education Press.

Xuedong Shi was born in Huhhot, Inner Mongolia, China in 1974. He received his MA degree in translation in Middlesex University, Britain, in 2004. He is currently a lecturer in the Foreign Language Department, Beijing Information Science University, Beijing, China. His academic research mainly focuses on translation and applied linguistics. 